Check for updates

St Leonard's Practice, St Leonards, Exeter, UK

2 Department of Primary Care and Public Health, Imperial College London, London, UK

3 Department of Public Health and Primary Care, University of Cambridge, Cambridge, UK

Correspondence to: M Roland mr108@cam.ac.uk

Cite this as: BMJ2020;370:m3709 http://dx.doi.org/10.1136/bmj.m3709 Published: 28 September 2020

\title{
Covid 19: a fork in the road for general practice
}

\author{
We must choose a personal not an impersonal future \\ Denis Pereira Gray, ${ }^{1}$ George Freeman, ${ }^{2}$ Catherine Johns, ${ }^{1}$ Martin Roland ${ }^{3}$
}

Covid-19 has produced the biggest change in the organisation of UK general practice for 200 years. As in many countries, face-to-face consultations have fallen to about $10 \%$ of their previous level and most contacts are now provided remotely using symptom checkers, electronic messaging, and phone or video consultations. Several of these changes may be permanent, with fewer face-to-face consultations in future. Opportunity and danger are two aspects of change: both now apply to general practice.

GPs currently have quieter waiting rooms, fewer locums, and reduced regulatory burdens such as from Care Quality Commission inspections. However, normal workload is returning, and while remote consulting makes access much easier for some patients, there is a real risk that general practice will suddenly become less personal. Worryingly, remote consultations may increase overall GP workload and exclude patients without internet access. ${ }^{1}$

\section{Continuity}

This colossal change in organisation occurred just when research on the doctor-patient relationship had reached new heights. Over many years, research on the value of continuity of care has progressively strengthened. As early as 1999, patient enablement (empowering people to undertake self-care) was found to be significantly related to patients "knowing the GP well” and to longer consultations. ${ }^{2}$

Subsequently, numerous observational studies have shown that continuity of care is significantly associated with higher patient satisfaction, better adherence to medical advice, better adherence to prescribed medication, better take-up of personal preventive medicine, fewer emergency department visits, and fewer admissions to hospital, especially for older people. ${ }^{34}$ Furthermore, two recent systematic reviews, one of them focused on primary care, showed that continuity of care by doctors is associated with reduced mortality. ${ }^{56}$

Patients greatly value empathy shown by GPs. Empathy is associated with significantly greater patient satisfaction and enablement ${ }^{7}$ along with fewer metabolic complications, reduced patient anxiety, ${ }^{8}$ and, strikingly, reduced all-cause mortality in people with diabetes. ${ }^{9}$ GPs can be proud of what they can achieve, but empathy cannot be provided by symptom checkers and electronic messaging.

With fewer face-to-face consultations, what can be done to ensure that the benefits of high quality consultations and continuity of care can be realised while avoiding general practice becoming an impersonal call centre? We believe there are opportunities, and the Royal College of General
Practitioner's decision to "re-invigorate relationship-based medicine" is encouraging. ${ }^{10}$

The first priority is to reverse the decline in continuity of care, which was evident well before the pandemic and fuelled by access pressures, larger practices, and increased part time working. If continuity continues to fall, patient safety will be undermined, organisational inefficiency will grow, and collusion of anonymity (when no one in a practice takes personal responsibility for a patient) will become widespread.

With more flexibility in working patterns, new approaches to consulting can be designed to improve continuity of care by, for example, ensuring that electronic messages and requests for phone calls are answered by the patient's own GP whenever possible. Many GPs find remote consulting easier with patients they know, and patient satisfaction is significantly better when GPs have responsibility for a defined lists of patients rather than adopting combined lists, ${ }^{11}$ though the potential of continuity within very small teams in larger practices should be evaluated.

\section{Longer consultations}

Fewer face-to-face contacts may make it possible to normalise 15 minute consultations. Longer consultations are both more patient centred and less stressful for clinicians, and the UK is an international outlier in its reliance on short consultations. ${ }^{12}$ The covid-19 crisis provides an opportunity to make general practice more personal.

The best features of high quality face-to-face consultations should be incorporated where possible into remote contacts with patients. The price of fewer physical examinations and fewer non-verbal cues is currently unknown but could include a reduction in quality of care. Research is urgently needed to identify what can and cannot be handled safely and effectively with remote consultation. Can trusted relationships be built this way, for example? Some patients already feel disempowered by losing their ability to make appointments.

Demand can be modified to free-up time for longer consultations. Some practices report annual face-to-face consultation rates as low as two per patient when using personal rather than combined lists and introducing 15 minute consultations. ${ }^{13}$ This approach might become more widespread if alternatives to face-to-face consultations allowed GPs to use their time more efficiently. Policy makers should be encouraged by the evidence thatshows how much healthcare costs can be reduced with better continuity of GP care. ${ }^{14}$ 
A key question for all countries is which changes to keep or discard after the pandemic. In the UK, general practice faces a choice between a personal or an impersonal future. The pandemic could be a spur for self-governing practices to win efficiencies by using alternatives to face-to-face consultations when possible, providing 15 minute consultations in the clinic, and maximising continuity of care in both.

Competing interests: We have read and understood BMJ policy on declaration of interests and have no relevant interests to declare.

Provenance and peer review: Not commissioned; externally peer reviewed.

1 Salisbury C, Murphy M, Duncan P. The impact of digital-first consultations on workload in general practice: modelling study. J Med Internet Res 2020;22:e18203.

doi: 10.2196/18203 pmid: 32543441

2 Howie JG, Heaney DJ, Maxwell M, Walker J), Freeman GK, Rai H. Quality at general practice consultations: cross sectional survey. BM/1999;319:738-43. doi: 10.1136/bmj.319.7212.738 pmid: 10487999

3 van Walraven C, Oake N, Jennings A, Forster AJ. The association between continuity of care and outcomes: a systematic and critical review. J Eval Clin Pract 2010;16:947-56. doi: 10.1111/j.1365-2753.2009.01235.x pmid: 20553366

4 Pereira Gray D, Sidaway-Lee K, White E, Thorne A, Evans P. Improving continuity: the clinical challenge. InnovAiT 2016;9:635-45doi: 10.1177/1755738016654504.

5 Pereira Gray D, Sidaway-Lee K, White E, Thorne A, Evans PH. Continuity of care with doctors-a matter of life and death? A systematic review of continuity of care and mortality. BMJ Open 2018;8:e021161. doi: 10.1136/bmjopen-2017-021161 pmid: 29959146

6 Baker R, Freeman GK, Haggerty JL, Bankart MJ, Nockels KH. Primary medical care continuity and patient mortality: a systematic review. Br J Gen Pract 2020;70:e600-11. doi: 10.3399/bjgp20X712289. pmid: 32784220

7 Mercer SW, Jani BD, Maxwell M, Wong SY, Watt GCM. Patient enablement requires physician empathy: a cross-sectional study of general practice consultations in areas of high and low socioeconomic deprivation in Scotland. BMC Fam Pract 2012;13:6. doi: 10.1186/1471-2296-13-6 pmid: 22316293

8 Derksen F, Bensing J, Lagro-Janssen A. Effectiveness of empathy in general practice: a systematic review. Br J Gen Pract2013;63:e76-84. doi: 10.3399/bjgp13X660814 pmid: 23336477

9 Dambha-Miller H, Feldman AL, Kinmonth AL, Griffin SJ. Association between primary care practitioner empathy and risk of cardiovascular events and all-cause mortality among patients with type 2 diabetes: a population-based prospective cohort study. Ann Fam Med2019;17:311-8. doi: 10.1370/afm.2421 pmid: 31285208

10 Royal College of General Practitioners. Policy and campaigning priorities 2020-23. https://www.rcgp.org.uk/policy/policy-and-campaigning-priorities-2020-23.aspx\#: :text=Reducing\%20unnecessary\%20general\%20practice\%20workload,general\%20practice\%20as\%20a\%20career.\&text=Encouraging\%20models\%20of\%20general\%20practice,that\%20are\%20right\%20for\%20them.

11 Baker R, Streatfield J. What type of general practice do patients prefer? Exploration of practice characteristics influencing patient satisfaction. Br J Gen Pract 1995;45:654-9. https://bjgp.org/content/bjgp/45/401/654.full.pdf.pmid: 8745863

12 Irving G, Neves AL, Dambha-Miller $\mathrm{H}$, etal. International variations in primary care physician consultation time: a systematic review of 67 countries. BMJ Open 2017;7:e017902. doi: 10.1136/bmjopen-2017-017902 pmid: 29118053

13 Sidaway-Lee K, Gray DP, Evans P. A method for measuring continuity of care in day-to-day general practice: a quantitative analysis of appointment data. Br J Gen Pract 2019;69:e356-62. doi: 10.3399/bjgp19X701813. pmid: 30803982

14 De Maeseneer JM, De Prins L, Gosset C, Heyerick J. Provider continuity in family medicine: does it make a difference for total health care costs? Ann Fam Med 2003;1:144-8. doi: 10.1370/afm.75 pmid: 15043375

This article is made freely available for use in accordance with BMJ's website terms and conditions for the duration of the covid-19 pandemic or until otherwise determined by BMJ. You may use, download and print the article for any lawful, non-commercial purpose (including text and data mining) provided that all copyright notices and trade marks are retained. 